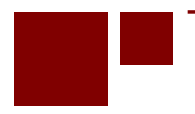

C E N T E R for RETIREMENT RES E A R C H at BOSTON COLLEGE

\title{
THE INTERCONNECTED RELATIONSHIPS OF HEALTH INSURANCE, HEALTH, AND LABOR MARKET OUTCOMES
}

\author{
Matthew S. Rutledge \\ CRR WP 2016-2 \\ July 2016
}

\author{
Center for Retirement Research at Boston College \\ Hovey House \\ 140 Commonwealth Ave \\ Chestnut Hill, MA 02467 \\ Tel: 617-552-1762 Fax: 617-552-0191 \\ http://crr.bc.edu
}

\begin{abstract}
Matthew S. Rutledge is a research economist at the Center for Retirement Research at Boston College. The research reported herein was performed pursuant to a grant from the U.S. Social Security Administration (SSA) funded as part of the Retirement Research Consortium. The opinions and conclusions expressed are solely those of the author and do not represent the opinions or policy of SSA, any agency of the federal government, or Boston College. Neither the United States Government nor any agency thereof, nor any of their employees, makes any warranty, express or implied, or assumes any legal liability or responsibility for the accuracy, completeness, or usefulness of the contents of this report. Reference herein to any specific commercial product, process or service by trade name, trademark, manufacturer, or otherwise does not necessarily constitute or imply endorsement, recommendation or favoring by the United States Government or any agency thereof.

(C) 2016, Matthew S. Rutledge. All rights reserved. Short sections of text, not to exceed two paragraphs, may be quoted without explicit permission provided that full credit, including (C) notice, is given to the source.
\end{abstract}




\begin{abstract}
About the Center for Retirement Research
The Center for Retirement Research at Boston College, part of a consortium that includes parallel centers at the University of Michigan and the National Bureau of Economic Research, was established in 1998 through a grant from the Social Security Administration. The Center's mission is to produce first-class research and forge a strong link between the academic community and decision-makers in the public and private sectors around an issue of critical importance to the nation's future. To achieve this mission, the Center sponsors a wide variety of research projects, transmits new findings to a broad audience, trains new scholars, and broadens access to valuable data sources.
\end{abstract}

Center for Retirement Research at Boston College

Hovey House

140 Commonwealth Ave

Chestnut Hill, MA 02467

Tel: 617-552-1762 Fax: 617-552-0191

http://crr.bc.edu

Affiliated Institutions:

The Brookings Institution

Massachusetts Institute of Technology

Syracuse University

Urban Institute 


\begin{abstract}
The Affordable Care Act (ACA) has greatly increased the proportion of non-elderly Americans with health insurance. One justification for the ACA is that improving individuals' access to health insurance would improve their health outcomes, mostly by increasing the probability that they have a regular source of care. Another is that increasing the availability of health insurance outside of employment reduces the "job lock" that ties poorly matched workers to their jobs only because they want to maintain coverage. This study reviews the literature on the relationships between health insurance and health, between health and work, and between health insurance and labor market outcomes directly. The review uses evidence from recent policy expansions in Oregon and Massachusetts, and among Social Security disability beneficiaries and Medicare enrollees, to evaluate the extent to which expansions have the expected effects on labor market outcomes, indirectly and directly.
\end{abstract}

This paper found that:

- Health insurance generally improves health. The gains in mental health are the most consistent across studies, though most studies also find notable improves in physical health measures, including mortality.

- Greater health generally allows for increased labor supply, though the strength of this relationship depends crucially on whether the health measure is objective or subjective, the group under consideration, and the study’s strategy for accounting for the endogeneity of the relationship.

- Expanded access to health insurance increases transitions into self-employment and allows older workers to retire earlier, but the effect on labor force participation, employment, and job mobility is less clear.

The policy implications of this paper are:

- Coverage expansions, including the ACA, are likely to result in a healthier and more productive pool of potential workers, and this effect is likely to increase labor supply.

- But not many studies have examined the full chain of relationships directly, by following recipients of expanded coverage to see if their improved health causally increased labor supply, so further work is needed in evaluating coverage expansions. 


\section{Introduction}

The Affordable Care Act (ACA) has already had a noticeable effect in reducing the proportion of uninsured American adults from 13.3 percent in 2013 to 10.4 percent in 2014 . $^{1}$ One justification for the ACA is that improving individuals' access to insurance would improve their health outcomes. In addition, increasing the availability of health insurance outside of employment reduces the "job lock" that ties poorly matched workers to their jobs only because they want to maintain coverage.

Advocates for health insurance reform suggest that improved health and reduced job lock would lead to better employment outcomes in the form of increased productivity and a more fluid, efficient labor market. On the other hand, workers may cut back on their hours to remain eligible for Medicaid or ACA premium subsidies. They may also retire sooner (CBO 2014), though this effect may be utility-improving.

This study examines the evidence for and against these claims both before and since implementation of the ACA. The study separately reviews the literature on: 1) how health insurance affects health outcomes; 2) how health affects labor market outcomes; and 3) how health insurance affects labor market outcomes directly, in addition to its effect on health.

The primary way in which health insurance affects health is through access to medical care, since having a regular source of care helps reduce the probability of a health shock or the development of a chronic health condition. And when shocks and new diagnoses occur, accessible care reduces the negative effects by encouraging management of recovery and maintaining healthy behaviors. Health insurance also reduces the probability of financial hardship due to unpaid medical bills; the resulting reduction in stress and uncertainty may have a direct positive effect on mental health. Levy and Meltzer (2004, 2008) and McWilliams (2009), in reviewing the literature, find that most studies - including quasi-experimental and experimental studies that are better designed to answer the research question than observation studies - report a positive effect of health insurance on health. This study first updates these reviews to reflect new natural experiments such as the Massachusetts health reform and

\footnotetext{
${ }^{1}$ Estimates from the Current Population Survey Annual Social and Economic Supplements from March 2014 and 2015; previous years' estimates are not comparable because the questions identifying insurance status changed with the 2014 survey. Results from the Gallup-Healthways Well-Being Index, which is more up-to-date and has been asked consistently over time, are similar: the uninsured rate fell from 18.0 percent in the fourth quarter of 2013 to 11.6 percent in the third quarter of 2015, though the uninsured rate has been roughly constant throughout 2015.
} 
Medicare Part D, and actual experiments such as the Oregon Medicaid Study and the Social Security Accelerated Benefits Demonstration.

Second, the study examines how health affects work at different points in the lifecycle. Currie and Madrian's (1999) literature survey points out that studying the relationship between health and labor market outcomes requires accounting for potential endogeneity. Endogeneity may arise because of measurement concerns like justification bias, which may lead individuals who are out of work to exaggerate the degree to which their health prevents them from finding or retaining a job, or reverse causality, where working either helps or harms the worker's health. This study reviews recent attempts to resolve the endogeneity problem in estimating the relationship between health and work. It also examines how public policy has been reformed to encourage work among the least healthy by, for example, decreasing work disincentives in the public disability programs and adding discrimination protections for the disabled. Finally, it reviews the few studies that have examined the full chain of interest: how increased availability or generosity of health insurance affects health, which then increases labor supply.

Third, the project examines how health insurance directly affects labor market outcomes, not through its influence on health but through reducing job lock - the idea that suboptimal employer-employee matches persist because the worker's best option for health insurance is at that job (Gruber and Madrian 2004). Job lock has been shown to reduce job mobility and selfemployment. It may also induce older workers to postpone retirement longer than they would like. Policy reforms aimed at increasing the portability of coverage or expanding access to insurance outside of the employment relationship should, at least theoretically, reduce job lock, but the results are mixed. This project reviews the literature to establish how job lock has changed over time and with policy reforms, and examines the initial impact on job lock from the ACA.

This survey of the literature aims to improve our understanding of how increased health coverage after implementation of the ACA is likely to affect health and labor market outcomes throughout the lifecycle. It concludes that health insurance generally improves health, especially mental health; that healthier workers have greater labor supply; and that increased availability of health insurance outside of employment increases the ability of workers to transition to selfemployment and retirement. But more research is needed to establish the extent to which health improvements induced by expanding health insurance coverage allow for better labor market 
outcomes and the extent to which more easily available coverage directly improves the fluidity of the labor market.

\section{The Effect of Health Insurance Coverage on Health}

Every few years, health economists review the literature on how health insurance coverage affects health, who benefits the most from coverage, and the mechanisms by which coverage might improve health. ${ }^{2}$ These reviews tend to find a consistent positive correlation between health insurance coverage and health across a wide range of studies, but simply finding this correlation is not enough to know that increasing coverage will improve health widely.

Health insurance is not assigned randomly, which means that the covered and the uncovered differ not only in observable characteristics - for which researchers can control - but also in traits that are unobservable. For example, the "young invincible" cohort of workers in their teens and twenties, who have the resources to purchase insurance but nonetheless eschew coverage unless mandated to buy it, may be less risk averse, which would be correlated with both low coverage rates and risky, unhealthful behavior. Furthermore, the causality may be backward: health insurance might appear to cause better health because worse health causes low coverage rates, if insurers are able to pick out only the lowest-risk applicants or rescind coverage for the high-risk (before the ACA prohibited rescission), or the unhealthy are unable to work enough hours to gain employer coverage. Endogeneity - whether arising because of omitted variables like risk aversion, or reverse causality through advantageous selection and rescission likely complicates the observed relationship between health insurance and health.

Recent reviews by Levy and Meltzer (2004, 2008) and McWilliams (2009) stress that researchers interested in health insurance policy should focus on experiments or quasiexperimental studies, rather than on observational studies that do little to account for endogeneity. Their review first examines the one true experiment conducted by RAND, and then details the quasi-experiments that rely on policy changes.

The RAND Health Insurance Experiment. The number of true experiments - which give coverage to a randomly selected treatment group, and observe how their outcomes differ from an otherwise-identical control group - was for a long time limited to just one: the RAND Health

\footnotetext{
2 Brown, Bindman, and Lurie (1998), IOM (2002), Hadley (2003), Levy and Meltzer (2004, 2008), McWilliams (2009)
} 
Insurance Experiment (HIE). The HIE randomly assigned health insurance plans with varying coinsurance rates and out-of-pocket limits to residents of six U.S. cities.

The HIE results indicate that enrollees with more generous coverage use more medical care, but the observed effect on their health status depends crucially on whether the health measure is objective or subjective (Newhouse et al 1993; Dow et al 1997). On nearly all subjective health measures such as self-assessed health status on a 5-point scale, low-income recipients of free-care plans actually report worse health. But the RAND researchers attribute this counterintuitive result to reporting error: they received more medical care, so they became better aware of their illnesses and any natural health declines. In contrast, objective health measures such as mortality, blood pressure, and anemia were all better in the follow-up period for free-care recipients than these same measures for similar individuals with cost sharing, who received less medical care. The authors conclude that obtaining coverage is good for one's health but caution that conclusions based solely on subjective measures may be misleading.

The HIE results also differ among subgroups: in particular, low-income persons with hypertension had lower blood pressure when they were assigned a plan with no cost sharing (Brook et al 1983). Keeler et al (1985) attribute this success to the finding that they were more likely to visit the doctor and have their hypertension diagnosed and treated.

The RAND HIE is regarded as the gold standard in evaluating the effect of health insurance generosity on utilization and health status, but it may have only limited application to our understanding of the health differences between the uninsured and the insured in recent times. Levy and Meltzer (2004) point out that the HIE was set up to compare insurance coverage only on the intensive margin; no group was randomly assigned to the uninsured group, perhaps out of fear that they would obtain coverage on their own and corrupt the experiment, or out of ethical concerns about leaving one group with no coverage. The HIE was also conducted nearly 40 years ago, when health insurance markets were less well-developed, so that the pool of uninsured Americans who could be assigned coverage was different than today's uninsured, or even the uninsured pre-ACA. And improvements in medical practices and technology have likely widened the difference between those with regular access to medical care and those who mostly seek care only in emergencies (McWilliams 2009). Even if the HIE were the perfect experiment, its scale and expense make it unlikely to ever be repeated in such a comprehensive way. 
Quasi-Experiments. Instead, modern researchers rely on quasi-experiments, which use policy changes that separate similar treatment and control groups more naturally (hence the alternative term, "natural experiments"); the groups are meant to be similar in every way except for their access to coverage. Exogenous policy changes vary in size: they may only affect a small group, as with budget-related coverage cutbacks for veterans (Fihn and Wicher 1988), or they may be more widespread, as with older Americans aging into Medicare eligibility (e.g., Card, Dobkin, and Maestas 2008). Other quasi-experiments take advantage of instrumental variables that are associated with health insurance coverage but not directly associated with health, except through coverage. For example, Hadley and Waidmann (2006) use spouse's union status as an instrument, because it should be correlated with coverage - through the increased availability of family plans - but not with the other spouse's health. The researchers then examine the relationship between health and the probability of coverage predicted by those instrumental variables - rather than actual coverage itself - which (if the instrument is valid) removes the concerns about endogeneity.

In contrast to the RAND HIE, but consistent with the vast majority of observational studies, most quasi-experiments documented by Levy and Meltzer $(2004,2008)$ and McWilliams (2009) conclude that health insurance does make adult enrollees healthier. ${ }^{3}$

Many of these studies take advantage of the fact that most uninsured Americans become eligible for Medicare coverage at age 65. Card, Dobkin, and Maestas (2008) find only modest improvements in self-reported health status and no statistically significant change in mortality upon Medicare eligibility at the population level in cross-section. Finkelstein and McKnight (2005) similarly find no effect on mortality after Medicare's implementation in 1965. But studies using other techniques report more positive effects. Decker and Remler (2004) use a triple-differences framework, comparing the differential changes in high- and low-income adults before and after age 65 in the United States and Canada, finding that lower coverage rates pre-65

\footnotetext{
${ }^{3}$ Levy and Meltzer $(2004,2008)$ also review studies of how health insurance affects the health of children and pregnant women, and the evidence for improved health is more mixed than it is for adults. A series of papers by Currie and Gruber (1996a, 1996b, 1997) find clear positive effects: Medicaid expansions led to declines in mortality in infancy and childhood and declines in the incidence of low birthweight. Hanratty (1996) also finds improvements in infant mortality and birth weight after Canada implemented national health insurance in the 1960s. In contrast, Haas et al (1993a, 1993b) find no effect on birth outcomes among mothers and infants who gain coverage from Healthy Start in Massachusetts in 1985, except for a decrease in caesarean sections. And more recently, Almond and Doyle (2011) find that after California required insurance plans to cover two full calendar days after childbirth, the extra time in the hospital for children born just after midnight resulted in no difference in infant readmission rates nor infant mortality compared to children born just before midnight.
} 
explain more than half of the income-related gap in self-reported health in the United States. Polsky et al (2006) and McWilliams et al (2007) follow previously uninsured adults longitudinally and find that acquiring coverage slows the rate of age-related health decline.

Other studies have attempted to account for unobservable differences between the uninsured and privately insured using instrumental variables. The studies have generally found that the privately insured are statistically significantly healthier and have greater access to care (Pauly 2005; Dor, Sudano, and Baker 2006; Hadley and Waidmann 2006). But these studies have been criticized for their choice of instruments; some of the proposed variables, such as involuntary job loss, immigration status, the state-level unemployment rate, and marital status, have been shown to affect health directly, making them invalid instruments for health insurance coverage (Levy and Meltzer 2008, McWilliams 2009).

In addition, some studies have compared enrollees who lose coverage to those who maintained coverage when budgetary pressure induced cutbacks. Lurie et al (1986) find that beneficiaries kicked off of Medi-Cal in 1982 had significant increases in blood pressure. Fihn and Wicher (1988) found that patients at the Seattle Veterans Administration Medical Center in 1983 whose benefits were terminated had substantial increases in blood pressure and were much more likely to report health declines than those who maintained coverage. These programs were both covering relatively low-income populations on a much smaller scale than Medicare or private insurance, and so the external validity of these results to a larger population is unknown. In addition, whereas most policy reforms have aimed at increased coverage, these studies estimate the effects of coverage cutbacks, and the effect of insurance coverage on health may not

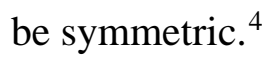

Across studies, as expected, the gains in health are especially strong among previously uninsured adults with chronic conditions such as HIV/AIDS, cardiovascular disease, or diabetes that require management and regular access to care (Goldman et al 2001; McWilliams et al 2007). Patients requiring acute care after a car accident, heart attack, or other events requiring immediate care such as a stroke or hip fracture also receive more and better care and have lower mortality rates (Doyle 2005; Volpp et al 2003; Card, Dobkin, and Maestas 2007).

\footnotetext{
${ }^{4}$ To my knowledge, no recent studies have examined the effect of coverage loss on health. Garthwaite, Gross, and Notowidigdo (2014) examine reductions in Tennessee's Medicaid coverage, but focus entirely on labor market outcomes rather than health.
} 
The use of quasi-experiments, rather than simpler observational studies, appears to be increasing. In Levy and Meltzer’s earlier review (2004), they categorize only three out of 131 studies in the Institute of Medicine’s (2002) review as quasi-experiments or experiments. ${ }^{5}$ But the tide turned soon after: both Levy and Meltzer (2008) and McWilliams (2009) report that more recent research has tended to use quasi-experimental techniques rather than simply relying on observed correlations.

Indeed, in the years since these reviews, more quasi-experimental studies have taken advantage of recent policy changes to identify otherwise-similar treatment and control groups and compare their health outcomes. ${ }^{6}$ In fact, two policy changes might be better characterized as experiments, finally breaking the RAND HIE’s hold as the only true experiment.

The Oregon Medicaid Study. The larger and better-known of the two new experiments took place in Oregon. In 2008, after prior budgetary cutbacks, the Oregon state government announced plans to expand Medicaid to 10,000 additional low-income enrollees other than the “categorically eligible” (children, pregnant women, the disabled, the elderly, and welfare beneficiaries). Nearly 90,000 individuals registered for a chance to obtain coverage via lottery. Finkelstein et al (2012) obtained permission to link lottery registrants to public records from hospitals, mortality records, and the TransUnion credit bureau, and supplemented this administrative information with surveys of both the winners and losers of the lottery. Lottery losers make for a suitable control group because they were just as motivated to seek coverage as the lottery winners, and Finkelstein et al demonstrate that the two groups are similar in observable characteristics. ${ }^{7}$

\footnotetext{
${ }^{5}$ This statistic is cited only in McWilliams (2009), not Levy and Meltzer's own work (2004). The statistic is based on Levy and Meltzer's categorization of the studies cited in IOM (2002).

${ }^{6}$ Other recent work has focused on the strong relationship between health coverage and medical utilization, but not health outcomes per se. Taubman et al (2014) find that Oregon lottery winners were actually more likely to use the emergency department (ED) than the control group, contrary to predictions that ED use would fall when the previously uninsured became less likely to use the ED as a substitute for non-emergency office visits. DeLeire et al (2013) find that, after Wisconsin expanded Medicaid to low-income childless adults in 2009, outpatient and emergency room visits both increased substantially, while preventable inpatient hospitalizations declined. Coey (2015) finds that 19-year-olds who age out of Medicaid eligibility see a sharp decline in office visits and medical expenditures.

${ }^{7}$ Lottery winners who did not obtain coverage because they chose not to submit the proper paperwork, or were deemed ineligible when they filed, were included in the treatment group to ensure that motivation for insurance coverage was held constant between treatment and control. Finkelstein et al (2012) randomly selected a subsample of lottery losers to obtain a control group of approximately the same size as the treatment group. The one statistically significant difference between the two groups was that the treatment group was more likely to respond
} 
The results of Oregon's experiment suggest that winning the lottery greatly increased access to health care, decreased unmet health needs, and virtually eliminated catastrophic out-ofpocket expenditures (Baicker et al 2013). Positive outcomes, however, were not limited to access and financial conditions. The coverage expansion led to a substantial and statistically significantly improvement in depression screenings, and lottery winners were about 10 percent more likely to report improved quality of life, particularly in self-reported mental health.

One concern is that, at least through the first two years, coverage had only a weak positive effect on physical health conditions. Blood pressure readings, hypertension, and high cholesterol failed to improve. Though diabetes diagnoses increased and diabetes treatment increased, glycated hemoglobin readings - which indicate the degree to which diabetes is kept in check - were virtually unchanged. But Carroll, Frakt, and Richardson (2013) point out that the experiment - even with 12,000 individuals combined between the treatment and control groups is likely underpowered. The fact that pre-experiment rates of high blood pressure, hypertension, high cholesterol, and diabetes were small suggests that not much improvement could be expected. Furthermore, two years may be too short a period to expect substantial improvements in physical health conditions; a short-run effect that is expected to be small is even harder to find in an underpowered experiment.

The Social Security Accelerated Benefits Demonstration. The other experiment conducted in the last decade was the Social Security Accelerated Benefits (AB) Demonstration, conducted among Social Security Disability Insurance (SSDI) beneficiaries. This demonstration came about because of concerns that the 24-month waiting period for Medicare eligibility (or 29 months after onset of disability) was unfair to individuals whose health needs had already been demonstrated to be severe enough to prevent work (Weathers et al 2010). The Ticket to Work legislation aimed at removing barriers to workforce reentry authorized a demonstration project that would waive the waiting period for some SSDI beneficiaries. Between 2007 and 2009, researchers recruited participants during their first six months of SSDI who lacked health insurance. About half of the participants were randomly assigned to receive a health benefits

to the survey, but the difference is substantively small (1.6 percentage points off of a mean of 51 percent) and does not appear to affect the differences in characteristics between the two groups. 
package. ${ }^{8}$ In addition to the health benefits, 20 percent of the full sample received health care coaching and counseling designed to facilitate a return to work; the group receiving these extra services is the "AB-Plus” group, while the group receiving only the health benefit treatment is the “AB” group. The remaining half of the sample makes up the control group.

By the time of their one-year follow-up survey, members of both the AB and AB-Plus groups had seen statistically significant health improvements (Michaelopoulous et al 2012). ${ }^{9}$ Members of the two treatment groups were about 50 percent more likely to report that their health had improved from the baseline period, relative to the control group. Unlike the Oregon experiment, treatment group participants reported improvements in both physical and mental health conditions; however, as with Oregon, mental health improvements were more clear-cut. These improvements are consistent with increases in health care use and decreases in unmet needs, though more than half of each of the treatment group still reported at least one unmet medical need even with the health benefits. ${ }^{10}$

In summary, the only two true, large-scale experiments since the RAND HIE both indicate that insurance has at least a slight positive impact on health, particularly mental health. The Oregon experiment indicates that gaining coverage improved mental health, quality of life, and financial outcomes. And while physical health was not affected in any statistically significant way, neither can the Oregon authors rule out positive physical health effects for new Medicaid recipients. The AB Demonstration also finds improvements in mental health among SSDI beneficiaries gaining access to health coverage, and more substantial physical health improvements than in Oregon.

Massachusetts reform. The last decade has also seen new quasi-experiments arise as a result of policy reforms that increased coverage. The expansion of health insurance coverage in Massachusetts, implemented in 2007, served as a model for the ACA just a few years later, so

\footnotetext{
${ }^{8}$ The AB health benefits package appears to be more generous than Medicare, covering more types of care (including skilled nursing facilities) with lower co-insurance (only a small co-payment for most services). Unlike Medicare, however, the AB package had a total insurer-paid maximum of $\$ 100,000$; about 9 percent of participants reached the maximum, with enrollees with cancer accounting for the plurality (Weathers et al 2010).

${ }^{9}$ Health outcomes were essentially no different between the AB and AB-Plus groups.

${ }^{10}$ One curious outcome is that both treatment groups experienced a higher mortality rate (both 5.2 percent) than the control group (3.5 percent), and that these differences were statistically significant. Michalopoulos et al (2012) go through the possible explanations and conclude that the mortality disadvantage for the treatment group cannot be due to the experiment itself, and is most likely due to random chance.
} 
researchers have been following its outcomes closely. Like the federal law, the Massachusetts reform expanded Medicaid; created an exchange of private plans with standardized benefits, guaranteed issue, guaranteed renewal, and no rescission; required individuals to attain coverage or pay a penalty when filing their tax returns; and required employers (other than the smallest firms) to offer coverage to their workers (Holahan and Blumberg 2006).

While most research on Massachusetts has focused on the reform's effect on insurance coverage and access to health care, ${ }^{11}$ the studies examining its effect on health outcomes are universally positive. Most of these studies use nationally representative datasets - the Behavioral Risk Factor Surveillance System (BRFFS) or National Health Interview Survey (NHIS) - in a difference-in-differences framework to compare the cross-sectional change in selfreported health status among Massachusetts residents to the change over that same time frame in similar states. ${ }^{12}$ Across studies, Massachusetts residents were more likely to report being in excellent health than before the reform’s implementation (Miller 2012a), with improvements in both physical and mental self-assessed health (Van der Wees, Zaslavsky, and Ayanian 2013). ${ }^{13}$ They also reported fewer days in poor physical or mental health, fewer days with health limitations or activity-limiting joint pain, and lower body mass index scores (Courtemanche and Zapata 2014). These results were even stronger for lower-income individuals.

Perhaps no study on Massachusetts reform has received more attention than Sommers, Long, and Baicker (2014). The authors compared mortality rates by cause of death in Massachusetts counties to a control group of counties in non-reform states chosen by propensity score matching to duplicate the Massachusetts’ counties demographic and economic profile. Mortality fell by 2.9 percent, or 4.5 percent just for causes of death that are amenable to health care; both estimates are statistically significant and are larger for the lower-income counties that stood to see the largest gains in coverage rates.

\footnotetext{
${ }^{11}$ See Sanzenbacher (2014) for a review.

${ }^{12}$ Courtemanche and Zapata (2014) use the BRFFS to compare Massachusetts to all other states, except those who passed health reforms of their own (Oregon, California, Maine, and Vermont). Van der Wees, Zaslavsky, and Ayanian (2013) also use the BRFFS, but limit the control group to New England states. Miller (2012a, 2012b) uses the NHIS and compares Massachusetts to the New England states plus New York, Pennsylvania, and New Jersey. Another study - Long, Stockley, and Dahlen (2012) - compares cross-sectional responses to the Massachusetts Health Reform Survey over time, and finds that more respondents report very good or excellent health in 2010 compared to 2006, but this study lacks a control group outside of Massachusetts.

${ }^{13}$ Miller (2012b) also reports large increases in the likelihood that a child's health is reported as excellent.
} 
The uniformity of the estimated positive effects of Massachusetts health reform - across metrics, data sources, control groups, and samples - stands in contrast to the less consistent results from Oregon's Medicaid expansion. Oregon saw improvements in mental health and self-assessed quality of life but little improvement in more objective physical health measures. While evidence on physical health metrics such as blood pressure and cholesterol readings is, as of this writing, less available for Massachusetts residents, the magnitude of the mortality effect suggests that coverage expansion clearly improved overall health. Even health insurance reform skeptics have conceded, to some degree. McArdle (2014) and Douthat (2014) run through potential confounders such as the possibility that the Great Recession had a less severe effect in Massachusetts, but they ultimately admit that coverage expansion can have a positive effect on mortality. McArdle also points out that the stronger effect in Massachusetts is in part due to the much larger scale of the quasi-experiment: 3.9 million Massachusetts residents versus 6,000 Oregonians; indeed, Frakt (2013) demonstrates how the larger sample size vastly reduces the confidence interval, making the effect easier to find.

Drug coverage expansions. Increased access to prescription drug coverage, notably with the implementation of Medicare Part D in 2006, has also added to the quasi-experimental knowledge about the effect of health coverage on health. As with the Massachusetts reform, expanded drug coverage appears to have had a positive effect on both physical and mental health. Not surprisingly, Part D coverage increased access to, and spending on, prescription drugs and increased adherence to drug regimens (e.g., Donohue et al 2011). McWilliams et al (2011) find that non-drug spending decreased, especially on inpatient and skilled nursing care, among Part D enrollees as a result of improved health. Ayyagari and Shane (2015) find that increased access to prescription drugs resulted in a decrease in depressive symptoms among the elderly.

The results are similar in Canada. Wang et al (2015) compare Québécois, who were mandated to have drug coverage starting in 1997, to residents of other provinces, where drug coverage is still not included in the national health insurance system. The results indicate that less-healthy enrollees saw substantial improvements in self-assessed health status, in part because increased drug coverage spilled over into more general practitioner visits. 
Conclusion. The question of whether health insurance coverage improves health outcomes is important in assessing the potential benefits of expanding coverage relative to the cost of coverage. Previous literature reviews (Levy and Meltzer 2004, 2008; McWilliams 2009) focusing on experimental and quasi-experimental evidence conclude that health insurance has at least a small but consistently positive effect on health, operating at least in part through greater access to care. Recent evidence from coverage expansions in Oregon and Massachusetts and among SSDI beneficiaries, as well as new drug coverage within Medicare, suggests that this conclusion may have been conservative. While Oregon's Medicaid expansion had only a small, statistically insignificant effect on physical health metrics, other researchers suggest that the confidence intervals are too wide to rule out positive effects. Other experiments and quasiexperiments, in contrast, suggest a stronger and more statistically significant effect of insurance coverage on health, most notably the Massachusetts reform, which has been associated with a large, statistically significant, and substantively meaningful reduction in mortality.

\section{The Effect of Health on Work}

This section addresses whether health improvements can be expected to lead to better labor market outcomes. One limitation that emerges from the existing research is that little attention is paid to health conditions that are particularly helped by health insurance coverage expansions. Instead, most studies focus on general health. Even studies that do examine conditions like mental health that are consistently found to be improved by coverage (as noted above) do not tend to directly examine the labor market consequences of obtaining coverage.

The idea of health as a component of human capital was formalized by Grossman (1972). Grossman points out that medical care (and by extension, health insurance that better enables one to pay for that care) is not valued per se; it is merely a means to an end, which is increasing or restoring one's health stock. Health, in contrast, is valued, both as a consumption good - life is less enjoyable when sick - and as a human capital investment. Grossman's model focuses on how health affects the time one can spend in market and non-market activities, but earlier models allowed for health to affect labor market productivity (Becker 1964). ${ }^{14}$ In either case, the models

\footnotetext{
${ }^{14}$ DeLeire and Manning (2004) combine these effects, laying out a theoretical model where poor health has both negative effects on labor demand because of productivity loss, and negative effects on labor supply because of absenteeism and decreased labor force participation. They conclude that poor health lowers hours worked and employment, but the inward shifts of both labor demand and labor supply result in an ambiguous effect on wages.
} 
imply that the size of the health stock, as well as the change in that stock - be it by investments that improve health such as medical care, preventive care, and healthy behaviors; or by depreciation and health shocks that decrease health - should be positively correlated with labor force participation, hours worked, and earnings.

Currie and Madrian (1999) survey the literature on how health affects labor market outcomes and find that the relationship depends on the health measure. ${ }^{15}$ Almost universally, the studies they review find that work limitations - somewhat tautologically - reduce labor force participation. Other health measures also have a large effect in some cases: for example, selfreported poor health (Bound et al 1996), obesity (Costa 1996), and mental health conditions such as psychosis and neuroses (Benham and Benham 1982). Other studies find smaller effects for depression (Ruhm 1992, Ettner 1997) and heart conditions (Kreider 1996).

Currie and Madrian also conclude that health generally has a large positive correlation with earnings; the typical study estimates that someone in poor health or with a work limitation earns at least 20 percent less than someone in good health and with no limitations. The relationships between health and hours worked or hourly wages depend crucially on the population studied. For example, Chirikos and Nestel (1985) find that a history of health problems is associated with lower earnings across race, but the explanation varies: whites see lower hourly wages and only a moderate effect on hours worked, while blacks' health history has almost no relationship with hourly wages but a large effect on hours worked.

Much of the literature on health's effect on labor market outcomes has focused on the decision to retire, in part because older workers are most likely to be at the margin of being healthy enough to work, and in part because of the availability of high-quality health and labor data in the Health and Retirement Study (HRS). A recent example is Munnell, Sanzenbacher, and Rutledge (2015), who examine whether HRS respondents are able to reach the retirement age that they expected to reach when they were age 58. They find that health - both the level of health at age 58, and the prevalence and severity of subsequent health shocks - is the primary reason for retiring earlier than expected. While this study examines the correlation between health and earlier-than-expected retirement, its conclusion concurs with research that attempts to

\footnotetext{
${ }^{15}$ This review focuses on the relationship between health in adulthood and working. A separate strand of the literature examines the long-run impact of child health on labor market outcomes (e.g., Case, Fertig, and Paxson 2005).
} 
account for the endogeneity of health in the retirement decision (Blau and Gilleskie 2001; Bound, Stinebrickner, and Waidmann 2010; Maurer, Klein, and Vella 2011). ${ }^{16}$ Still, Munnell, Sanzenbacher, and Rutledge find that only a moderate percentage of the earlier-than-planned retirement decisions can be explained by any single factor, including health. Indeed, workers appear to be retiring while most are still healthy enough to keep working (Coile, Milligan, and Wise 2016), suggesting that idiosyncratic and hard-to-observe factors are important.

While health clearly limits a worker's earnings and the time they spend in the workforce, employers also bear some of the costs of their workers' poor health. O’Brien (2003) reviews the literature on how health and health insurance affect employers and suggests that there is a strong "business case” for offering health insurance benefits to employees: the employer reaps some of the benefits in the form of lower absentee rates and greater productivity. In some studies cited by O’Brien, offering insurance appears to almost pay for itself, even leaving aside the hard-toestimate value of attracting and retaining high-quality employees. For example, Goetzel et al (2004) estimate the value of that lost productivity at \$300-\$400 (in 2004 dollars) per employee per year with hypertension, heart disease, depression, or arthritis. In the case of these diseases, these productivity costs are greater than the direct cost to the insurer (or self-insuring employer), so the health insurance essentially pays for itself.

Accounting for endogeneity. As discussed earlier, Currie and Madrian (1999) caution that most of the studies they survey do not attempt to account for the potential endogeneity of the relationship between health and labor market outcomes. One source of this endogeneity is justification bias: labor market non-participants may use their health as an excuse for why they are not working, even if their health is not objectively worse than a similar labor market participant, thereby overstating the relationship between health and labor outcomes (Bound 1991). Another is reverse causality: employment may decrease health, if jobs are dangerous or stressful, or increase health, if unemployment and non-participation lead to degraded health. ${ }^{17}$

\footnotetext{
${ }^{16}$ In contrast, French (2005) finds that health trails Social Security incentives as the top reason for retirement timing. ${ }^{17}$ Another criticism levied by Currie and Madrian (1999), as well as by Chirikos (1993) in another review, is that the literature focuses on older, white men. This focus is likely due to the availability of data from the National Longitudinal Study of Older Men, as well as the HRS and its predecessors. Pelkowski and Berger (2004) attempt to resolve the gap in the literature in a surprising way: by using the HRS, the very reason that older white men are overstudied. Using retrospective questions on health, they find that permanent health conditions have a large, statistically significant negative correlation with labor force participation, hours worked, and hourly wages. The negative relationship between permanent health conditions and wages are somewhat stronger for women, while men
} 
Subsequent research has attempted to answer these concerns about the endogeneity of the health-labor relationship. These studies use a variety of approaches, including modeling the endogeneity explicitly, using more plausibly objective health measures, and focusing on plausibly exogenous health shocks.

Cai (2010) explicitly allows for the endogeneity of health in a model of simultaneous equations. Using data from Australia, he finds that each one-point increase on a five-point scale of self-reported general health (poor to excellent) increases labor force participation by about 2 percentage points for men and over 3-4 percentage points for women.

Rather than rely on subjective health measures that are more likely to reflect justification bias and other sources of endogeneity and measurement error, Zimmer (2015) uses health measures that are more plausibly objective. The Medical Expenditure Panel Survey asks respondents about medical conditions, and assigns some of them the designation of "priority conditions" based on recommendations from the U.S. Department of Health and Human Services. Zimmer contends that these health measures are more objective because they (1) are asked outside of the employment context, in the health portion of the survey; and (2) the conditions are confirmed by physician consultation with follow-up treatment. He finds that priority conditions have a smaller negative effect on the probability of being employed full time than non-priority conditions, but they have a larger negative effect on hours worked, with larger declines in both outcomes if the respondent's employer does not provide health insurance.

Similarly, some studies exploit sudden, objectively measured health shocks, which are less likely to suffer from justification bias or reverse causality. Dano (2005) matches Danish working-age citizens who are hospitalized after a car accident to Danes who are not injured in car accidents, and finds that employment and earnings are lower even five years after the accident. Using Dutch data, Garcia-Gomez et al (2013) find that, following an acute hospitalization, employment falls by 7 percent and personal income by 4.5 percent and that both losses are permanent (lasting at least five years, until the data are censored).

Cancer diagnoses are another major source of plausibly exogenous and objective variations in health. A meta-analysis by de Boer et al (2009) finds that, not surprisingly,

have the stronger correlation between permanent conditions and hours worked. Meanwhile, temporary conditions have no statistically significant relationship with labor outcomes. The adverse relationship is strongest among permanent conditions that arise in the 40s for men and 30s for women. 
employment rates fall substantially after a cancer diagnosis. While the studies reviewed by Mehnert (2011) indicate that nearly 90 percent of cancer survivors return to work within two years, their labor market outcomes take a substantial hit. Short, Vasey, and Moran (2008) match older (age 55-65) cancer survivors to healthy controls and compare their outcomes two to six years after diagnosis. The survivors who were not diagnosed with a new cancer over that period were less likely to be working and work two to four hours less per week than the control group. Using the same data for a younger group (age 28-54), Moran, Short, and Hollenbeak (2011) actually find a larger employment decline: 3.5 hours for women and 5.5 hours for men, even without a new cancer diagnosis.

While cancer diagnosis provides an objective measure of health that is not likely to be misreported or underreported, health conditions that are more relevant to this review would be of a different nature: conditions for which obtaining health insurance coverage makes the difference between being able or unable to work. One such condition is mental illness; with regular access to care and a maintenance regimen, individuals with mental health conditions are more likely to be employed and have greater work hours (Bartel and Taubman 1979, 1986; Ettner 1997; Berndt et al 1998; Chatterji, Alegra, and Takeuchi 2011).

Disability insurance beneficiaries. Another way in which the unhealthy are distinctively categorized is as part of the evaluation process for public disability benefits. The degree to which individuals receiving public disability benefits are able to work has been a key element of evaluating the efficiency of the disability system. If recipients are able to work but are drawn into the program by low wages, a lack of fulfilling work, or stingy welfare benefits, the disability system may be better off reducing its generosity or refocusing its approach (Autor and Duggan 2006; Joffe-Walt 2013).

But most studies that estimate the work capacity of SSDI beneficiaries suggest that their ability to work is quite limited. These studies use the approach first outlined in Bound (1989), comparing SSDI beneficiaries to similar individuals who applied for benefits but were rejected. Since the rejected group has little reason to avoid work, it serves as a plausible hypothetical for the labor supply decisions of beneficiaries if they were not receiving benefits. Later refinements to this approach have limited the focus to applicants on the margin between allowance and denial by exploiting differences in the allowance rates of each examiner (Maestas, Mullen, and Strand 
2013) or appeals judge (French and Song 2014). The consensus estimate is that only 26-35 percent of successful applicants at the margin would work if they did not receive benefits. This estimate is very close to the 28 percent of SSDI and Supplemental Security Income (SSI) beneficiaries awarded benefits in 1996 who earned at least $\$ 1,000$ in at least one year among their first 10 years in the programs, though fewer than 4 percent worked enough to lose their benefits entirely (Stapleton, Liu, Phelps, and Prenovitz 2010).

While the work capacity of disability beneficiaries appears low, the Social Security Administration (SSA) has adopted reforms that reduce work disincentives in the event that a beneficiary can work. The Ticket to Work program, adopted in 2002, provides beneficiaries with benefit counseling, vocational rehabilitation, and training from state-run and private networks; postpones Continuing Disability Reviews while they participate in these programs; extends Medicare eligibility and offers a Medicaid buy-in after benefits are terminated; and allows for expedited reinstatement if beneficiaries reapply within five years (Stapleton et al 2008). But fewer than 3 percent of beneficiaries participated in Ticket to Work services in 2007, and while subsequent reforms aimed at encouraging private training networks to enroll participants did decrease the number of beneficiaries reporting unmet needs, the employment rate was essentially unchanged (Blyler, Hoffman, and Livermore 2013). These results suggest that, while public services help some disability beneficiaries get on the path to returning to work, that path is not well-trod.

The impaired should also have been helped by the Americans with Disabilities Act (ADA), but studies that evaluated its effect on labor market outcomes for the disabled shortly after its implementation in 1992 indicated that employment actually fell. The explanation given for this counterintuitive result is that having to make accommodations and losing the ability to terminate the employment of workers whose productivity declines due to health may make employers more apprehensive about hiring impaired workers with impairments in the first place. But subsequent research using more objective measures of health (Kruse and Schur 2003), focusing on how the ADA changed the legal context relative to each state's pre-existing laws (Jolls and Prescott 2004), or evaluating more aggressive state policies such as in California (Button 2016) find either no reduction in employment or the expected positive effect. These results indicate that the disabled have some untapped work capacity, but that strengthening legal protections may be necessary to get them back to work. 
Increasing health insurance coverage. This review is ultimately interested in how health coverage expansions affect health and, through improved health, labor market outcomes. But the literature on this linkage is surprisingly sparse. Most studies that examine health coverage expansions stop at examining their effect on health, while studies that examine the relationship between health and working usually do not have differences in health coverage available to exploit. Most of the studies that examine the full chain - health insurance affects health, health affects working - are limited to correlations, because health insurance is not randomly assigned. A recent example is Xu and Jensen (2012), who find no statistically significant difference in the amount of work missed for illness among individuals lacking health insurance compared to the insured in the HRS.

The RAND HIE, of course, provides an opportunity to examine health coverage that is explicitly randomly assigned. RAND researchers compared labor force participation rates by education level among individuals who were assigned free care relative to those who received insurance with cost sharing (Newhouse et al 1993; Dow et al 1997). They found important differences by gender and education level. Male high school dropouts receiving free-care insurance plans rather than cost-sharing plans saw a large (but just short of statistically significant) increase in their labor force participation rates, by about 9 percentage points more than similar men in plans with cost sharing. Both better- and less-educated women also saw larger increases if they were in free-care plans, but the effects were smaller than for lesseducated men and were statistically significant only for less-educated women. Better-educated men, however, increased their participation rates by almost the same amount irrespective of their insurance plan, so insurance seems not to have had an effect.

The Social Security AB Demonstration for SSDI recipients also examined labor market outcomes. In addition to health benefits, the AB-Plus group was offered vocational rehabilitation and career counseling, and Michalopoulos et al (2011) report substantial take-up of these services. But the effect on employment was minimal: only 10.5 percent of the AB-Plus ever worked in the year after the experiment began, which is almost exactly the rate for the everemployed among the AB group that received only health benefits, and only a statistically insignificant 1.2 percentage points more than the control group. These low employment rates emphasize that SSDI recipients - even among the group receiving extra help with their job search - are unlikely to be able to work. 
More recently, Andersen (2015) uses state-level policy changes to examine what happens when individuals with mental health conditions obtain coverage. He finds that mental health parity mandates - which require insurers in a state to treat mental health care the same as physical health care - have a positive effect on the probability of employment among individuals with the most severe mental distress and have a positive effect on hours worked and hourly wages for those with moderate distress.

Conclusion. The existing literature indicates that health and labor market outcomes are positively correlated, though the magnitude and statistical significance of that relationship differs widely depending on the health measure in use (including objective versus subjective), the group under consideration, and the study's strategy for accounting for endogeneity. Some public policy reforms, such as disability discrimination protections and mental health parity laws, have improved labor market outcomes for individuals with health limitations, but others, such as Ticket to Work, appear to have had little effect. The relative inconsistency of these results and the paucity of studies directly examining the question of interest in this review - the full chain of health coverage improving health, which then increases work - indicate that further research is needed.

\section{The Direct Effect of Health Insurance on Work}

The previous sections review the literature on how health insurance, via its effect on health, affects labor market outcomes. But health insurance also affects labor market outcomes directly, because in most countries it is provided either by employers or the government.

In the United States, the primary source of insurance coverage for the nonelderly is an employer, either the individual's or his spouse's. ${ }^{18}$ The provision of health insurance through the employment relationship encourages labor force participation. But it may also cause "job lock," which occurs when employees lacking another source of insurance with a comparable level of generosity remain in their jobs even when they would be better off in a different one. Job lock, conceptually, results in the persistence of suboptimal employer-employee matches and suppresses small business formation.

\footnotetext{
${ }^{18}$ In 2014, 71.1 percent of Americans ages 19-61 were privately insured. Among those with any health insurance, 83 percent had private insurance (Smith and Medalia 2015).
} 
Prior to the ACA, which made private insurance widely available outside of employment, most of the remainder of the insured obtained health coverage through government programs: Medicare for the elderly and disabled and Medicaid for the low-income. ${ }^{19}$ Because Medicaid requires that family income fall below a state-specified threshold, it provides a disincentive to participate in the labor force and to increase hours worked and earnings. Medicare does not have an income test but, as with Medicaid, the provision of insurance outside of employment provides one less reason to work.

This section updates previous reviews by Currie and Madrian (1999), Gruber (2000), and Gruber and Madrian (2004) that examined the relationships between labor market outcomes and both employer-sponsored health insurance and public coverage. The updated review focuses on how insurance coverage affects job mobility, labor force participation (including retirement timing), employment, and hours worked (mostly whether the individual has a full- or part-time schedule). ${ }^{20}$

Gruber and Madrian (2004) lay out a clear theoretical model of how health insurance affects job mobility and other employment outcomes. Their model envisions firms whose cost of offering health insurance differ, because of scale (costs are higher at small firms) or experience rating (some firms employ older or less healthy workers). Workers sort into firms based on the value each worker places on health insurance: those who value it more work for the firms that are able to offer it more cheaply, while workers who do not value health insurance work for firms for whom offering health insurance would be more costly. The inefficiency arises when a

\footnotetext{
${ }^{19}$ Other public programs also provide health insurance coverage, including Indian Health and Tricare, and the Department of Veterans Affairs offers direct provision of health care to some veterans, in particular those with service-related medical conditions.

${ }^{20}$ The provision of insurance through the employer, at least conceptually, also reduces wages, provided that employers strive to equate an employee's marginal revenue product with the full value of his compensation, including wages and fringe benefits. Though wages are clearly a labor market outcome, this review does not focus on the relationship between wages and insurance coverage because most studies examining the wage-insurance tradeoff are interested in quantifying the perceived value of health insurance and the efficiency of its provision through employers, rather than wages as a labor market outcome per se. Currie and Madrian (1999) review the literature to that point, which typically found that the wage-insurance tradeoff was nowhere near dollar-for-dollar. The relationship is complicated by unobservable characteristics such as ability: high-ability individuals demand both higher wages and more fringe benefits, and when researchers are unable to control for ability, the correlation between wages and fringes appears to be positive, not negative. Recent estimates using econometric strategies such as GMM, fixed effects models, or instrumental variables to get around unobservables have not been able to resolve this puzzle, finding either no tradeoff (Lehrer and Pereira 2007; Lubotsky and Olson 2015) or a small tradeoff that is much less than one-for-one (Olson 2002; Baicker and Chandra 2006; Adams 2007; Daneshvary and Clauretie 2007; Lluis and Abraham 2013; Anand 2013). The notable exception is Kolstad and Kowalski (2012), which finds that wages are reduced by almost the full cost of health insurance after Massachusetts' health reform.
} 
worker who values health insurance could achieve a higher level of productivity - and a higher cash wage - at another firm refuses to move because that firm does not offer insurance (or offers less generous plans).

Gruber and Madrian apply the basic structure of this model to other labor market decisions as well. A wage worker may have an idea for a profitable small business but may opt not to take the risk of self-employment if it means sacrificing insurance coverage or moving to the inefficient individual or small-group markets. An older worker may prefer to retire (and his employer may also prefer it) all else equal but keeps working if he would not be covered by a retiree health plan or Medicare. A welfare recipient may also opt to not work rather than put his Medicaid eligibility at risk. These realistic scenarios suggest that workers throughout the lifecycle and income distribution - and their employers - would benefit from easier access to health insurance outside of employment.

Job mobility. The focus of much of the literature has been on a narrow definition of job lock: the idea that workers do not switch employers more often because, even though their current job is less than optimal, they prefer their current employer-sponsored insurance coverage to the coverage in an alternative job (or lack thereof). Gruber and Madrian (2004) review 18 studies on job-to-job mobility and find strong evidence for job lock: in almost every case that considers whether workers have an alternative source of coverage such as their spouse's employer, workers dependent on their current employers for insurance are less likely to switch to another employer.

In the years since that review, public policy, implicitly or explicitly, has attempted to reduce job lock, committed to the idea that employees and employers would benefit from more fluid labor markets that result in better matches. The first reform to attempt to reduce job lock was the Consolidated Omnibus Reconciliation Act of 1985 (COBRA), which included a “continuation of coverage” provision to extend the option for workers to maintain their employer-sponsored health insurance coverage for up to 18 months after job separation (usually known as “COBRA coverage”). Gruber and Madrian (1994) find a large effect from continuation of coverage laws: job turnover increases by 10 percent in states that passed COBRA-like provisions. But in recent years, COBRA coverage is unlikely to have as large an effect, because take-up rates are quite low owing to the plans’ high prices; even in the midst of 
the Great Recession, when COBRA benefits were subsidized by the federal government, the take-up of COBRA benefits was still less than 50 percent (Bovbjerg et al 2009).

The reform that most explicitly aimed to address job lock was the Health Insurance Portability and Accountability Act of 1996 (HIPAA). HIPAA restricted the ability of insurers to exclude coverage for pre-existing conditions, along with enacting a number of reforms to the small-group and individual insurance markets aimed at increasing private coverage outside of large employers. The theory behind HIPAA is that those who feel the most tied to their jobs for insurance coverage are workers (or their families) with pre-existing conditions that make them expensive to insure; before HIPAA, these workers were essentially limited to job opportunities in large firms - and, in particular, the jobs they held before those conditions arose.

But HIPAA appears to have had only a small effect on job mobility. The implementation of HIPAA on a national basis makes it hard to evaluate, but Sanz-de-Galdeano (2006) points out that many states already had provisions in their insurance market regulations that were subsequently included in HIPAA. Using this variation across states, she finds only a small, statistically insignificant higher rate of job mobility in states with prior HIPAA-like regulations, suggesting that HIPAA would likely have very little impact on the fluidity of labor markets. ${ }^{21}$ Kapur $(2003,2004)$ also finds little impact from HIPAA on the rate at which workers transition into small firms, even among those with health conditions for which insurers may deny coverage. Sanz-de-Galdeano argues that HIPAA did not aim to make insurance affordable, so workers may have remained with their employers rather than risk less generous coverage and/or higher premiums at a new job.

More comprehensive coverage expansions, on the other hand, do aim to make insurance plans more affordable, while also making coverage less dependent on working for a specific employer. Like HIPAA, the Massachusetts health reform required insurers to sell plans to all comers (guaranteed issue), but it resolved the cost concerns left over from HIPAA by allowing more residents onto Medicaid and by creating a subsidized exchange of private insurance options. But as with HIPAA, the effect of Massachusetts' reform on employment has been very weak. Sachs (2013) finds no difference in job mobility, even among low-income workers who

\footnotetext{
${ }^{21}$ Adams (2004) does not explicitly testing for differences pre- and post-HIPAA, but does estimate the effect of insurance coverage on job mobility for each individual year from 1988-2000. He finds no trend break in the job lock effect post-1996, so his results concur with Sanz-de-Galdeano (2006).
} 
would see the greatest decrease in premiums (either through premium subsidies or Medicaid eligibility). Preliminary results from Coe et al (in progress) using tax records also suggest that the rate at which workers switch employers or move from large to small firms is no different in Massachusetts around the time of its reform than in any other state.

Most provisions of the ACA were implemented in 2014, so not enough data have been collected on the most affected groups to determine whether the ACA has eased job lock broadly. But the ACA changed the insurance available to one group almost immediately: young individuals were permitted to remain on their parents' insurance plans until their $26^{\text {th }}$ birthday. Bailey and Chorniy (2016) find that this “dependent care mandate” does not reduce job lock.

The results from implementation of HIPAA and Massachusetts health care reform, and preliminary results from the ACA, all indicate that job lock is generally not reduced by coverage expansions and reforms that allow for greater portability of coverage. One exception is reported in Hamersma and Kim (2009): state-level expansions in Medicaid after the mid-1990s welfare reform reduced job lock among unmarried women. Farooq and Kugler (2016) find that thosee same Medicaid expansions also allowed workers to switch to occupations that were riskier but had greater potential earnings.

Self-employment. Another labor market outcome that job lock could affect is the decision to start one's own business. Gruber and Madrian (2004) review only two papers concerned with transitioning into self-employment; these papers have conflicting results and both suffer from measurement error (Holtz-Eakin, Penrod, and Rosen 1996; Madrian and Lefgren 1998). But recent reforms such as changes to coverage expansions and to the deductibility of health insurance premiums for the self-employed provide an opportunity for better-identified models to re-examine this relationship.

The recent literature largely finds that job lock substantially limits the ability of workers to leave wage employment and start their own businesses and that this constraint is relaxed by policies that increase access to affordable coverage. Velamuri (2012) reports a statistically significant 10-percent increase in self-employment rates from the adoption of deductible health insurance premiums. When that deductibility was increased gradually from 25 percent before 1999 to 100 percent in 2003, Heim and Lurie (2010) find even larger effects; they attribute between one-third and one-half of the growth in the rate of self-employment over this period to 
this policy. Similarly, Fairlie, Kapur, and Gates (2011) find that reaching Medicare eligibility increases self-employment, and Niu (2014) finds an 8-percent increase in the self-employment rate after Massachusetts reform. On the other hand, Zissimopolous and Karoly (2007) find that men with alternative sources of coverage, usually through their spouse, are actually less likely to start their own businesses, but this counterintuitive result may reflect differences in unobservable characteristics such as risk aversion. In addition, Heim, Lurie, and Simon (2015) find that the ACA dependent care mandate has had little effect on self-employment among younger workers, but members of this age group is the least likely to start their own businesses. But on the whole, those looking to work for themselves appear to be helped by increased access to affordable health insurance.

Labor market outcomes at prime ages. Most of the studies that have examined how labor force participation and employment respond to health insurance availability among prime-aged individuals have focused on low-income single mothers, and in particular how Medicaid affects their entry into the labor force. The studies reviewed by Gruber and Madrian (2004) generally find no effect (Blank 1989; Meyer and Rosenbaum 2000; Decker 2003) or only a small effect (Yelowitz 1995; Montgomery and Navin 2000) from Medicaid benefit generosity or Medicaid eligibility expansions on labor force participation and employment. The only study that focuses on prime-aged men is Gruber and Madrian's (1997) study of COBRA coverage, which finds a small but statistically significant reduction in non-employment.

Because the ACA has expanded coverage to many different groups, not just low-income single mothers, an analysis of its effects will have to be conducted over a broader set of people. The Congressional Budget Office (2014) projects that, overall, hours worked and employment are likely to grow more slowly than they would have in the absence of the ACA, which received a great deal of attention among the ACA's critics. Elmendorf (2014) subsequently clarified that these projections are mostly due to more voluntary exits from the labor force. This projection implies that the labor force participation rate, especially at older ages, is likely to fall, with little effect on the unemployment rate or the rate at which workers who want to be full time will instead work only part time (underemployment).

These CBO projections are based in part on the experience in Massachusetts. Dubay, Long, and Lawton (2012) find no difference in the time trend in employment rates between 
Massachusetts and a set of control states; furthermore, the results do not differ by firm size, industry or, importantly, full-time versus part-time employment. Sanzenbacher (2014) also found no difference between Massachusetts and a group of control states in unemployment rates among men ages 55-64. But in line with the CBO's expectations, Sanzenbacher did find that the labor force participation rate for this group in Massachusetts declined by 1.3 percentage points between the 2000-2005 and 2007-2012 periods, a decline of nearly a full percentage point more than the next-lowest northeastern state (Pennsylvania at 0.4 percent).

Since both the Massachusetts and ACA reforms relied on increasing access to Medicaid, the response to past Medicaid expansions is relevant for determining the ACA's potential effect. Strumpf (2011) looks back to when Medicaid was first introduced and finds that, contrary to theoretical predictions, eligible women living in states that expanded Medicaid earlier reduced their labor supply relative to similar women in states that were slower to roll out Medicaid; if anything, the women gaining access to Medicaid increased their labor supply, which Strumpf attributes to improved health. Baicker et al (2014) find a negative but small and statistically insignificant effect of Medicaid expansion on employment and earnings, rejecting the large declines predicted by theory. In contrast, Garthwaite, Gross, and Notowidigdo (2014) find that when Medicaid access was reduced for budgetary reasons in Tennessee in 2005, employment increased substantially, especially among the childless adults who were most likely to lose coverage. Further research will be needed to resolve these contradictory results for whether the ACA’s Medicaid expansion will reduce labor force participation and employment.

Other public health benefit expansions are also relevant. When the U.S. Department of Veterans Affairs expanded health benefits in the mid-1990s, veterans at ages 55-64 increased their rates of non-employment and part-time employment relative to similar non-veterans, a result consistent with an easing of job lock (Boyle and Lahey 2010).

Retirement. Gruber and Madrian (2004) review the extensive literature on "retirement lock:” the concept that workers are reluctant to retire in the absence of employer-sponsored retiree health insurance (RHI) or Medicare eligibility. Gruber and Madrian report that having access to RHI has a positive effect on retirement, but the estimates range widely: the probability of retiring by age 65 increases by 4 to 15 percentage points and the retirement age decreases by anywhere from 6 to 24 months. 
Most of the literature has focused on RHI rather than Medicare because, until 2003, Medicare eligibility coincided with the Social Security Full Retirement Age (FRA), as well as the normal retirement age for many pensions and, perhaps, a social norm that age 65 was the age that people "should" retire. These factors meant that studies that attempted to isolate the effect of reaching Medicare eligibility had to rely on structural models, where results may be sensitive to the underlying assumptions. The structural models differ in their conclusions about the effect of Medicare eligibility on labor supply. Rust and Phelan (1997) and Blau and Gilleskie (2006, 2008) find minuscule effects of Medicare eligibility on retirement. In contrast, French and Jones (2011) find that postponing Medicare eligibility to age 67 would lead to a large increase in the retirement age, on the same order of their anticipated response to increasing the FRA to 67.

The 1983 Social Security Amendments did a favor for researchers by gradually increasing the FRA from 65 to 67, starting with the 1938 birth cohort. Because the Medicare eligibility age remained fixed at 65, a decoupling of the Medicare age and the FRA has allowed researchers to empirically estimate the effect of Medicare eligibility separately from Social Security incentives. Coe, Khan, and Rutledge (2013) focus on workers in the cohorts whose FRA increased and who most depend on Medicare for post-employment health insurance - those workers whose current source of insurance is the employer but who lack RHI. This group has a statistically significantly greater spike in retirement in the month of their $65^{\text {th }}$ birthday compared to individuals who are not reliant on their employer or those who will have RHI when they retire.

The results from the decoupling of Medicare, in combination with estimates of the effect of RHI, indicate that maintaining access to health insurance is a key component in the retirement decision. But initial results from the ACA suggest otherwise: Levy, Buchmueller, and Nikpay (2015) find essentially no trend break in retirement or part-time work at ages 55-64 either at ACA implementation in 2014 and no effect in states expanding Medicaid relative to nonexpanding states. The authors caution that the null effect could have resulted from citizens' concerns about the stability of health reform, such as uncertainty about the Supreme Court's rulings and the rocky rollout of the federal exchange website. Also, because they are using the Current Population Survey, which does not allow them to track workers over time, they are not able to compare workers based on their previous insurance status. The results may differ when 
data are released from longitudinal datasets such as the Survey of Income and Program Participation. $^{22}$

Conclusion. Labor economists have long made the argument that the provision of health insurance to most working-age Americans, either by employers or through a public program, introduces labor market frictions that suppress job mobility, encourage older workers to postpone retirement, and discourage low-income workers from seeking employment. Recent estimates suggest that job lock due to a desire to maintain employer health coverage does not suppress mobility as much as previous estimates had indicated but still find significant effects on transitioning to self-employment and into retirement. The recent evidence on how coverage expansions affect labor force participation and employment, on the other hand, is much more mixed.

\section{Conclusion}

This review provides a comprehensive description of three relationships. First, it finds that health insurance generally improves health, in particular mental health, but perhaps also physical health conditions and mortality. Second, it finds that improved health generally allows for an increased labor supply, and likely also labor demand, though efforts to improve labor market outcomes for the disabled have had mixed results. Third, it finds that expanded access to health insurance increases transitions into self-employment and allows older workers to retire earlier, but the effect on labor force participation and employment is unclear.

These results suggest that coverage expansions, including the ACA, are likely to result in a healthier and more productive pool of potential workers, and this effect is likely to increase labor supply. But surprisingly few studies actually follow workers over time after they gain coverage to see if their improved health actually increases the amount that they work. As the Massachusetts expansion matures, and as the ACA improves access to health insurance for the rest of the country (which may be slow, if several states hold out against Medicaid expansion), it

\footnotetext{
${ }^{22}$ In contrast, Heim and Lin (2014) find a small but statistically significant increase in retirement from full-time work in Massachusetts after health care reform, compared to residents of other northeastern states, even using crosssectional data.
} 
is imperative that researchers examine the extent to which health insurance improves labor market outcomes via better health.

Further research is also needed to resolve whether coverage expansions will ease job lock, allowing for more fluid labor markets that connect workers to their most productive and satisfying job matches and reducing the degree to which health insurance complicates their search. Researchers may also examine whether a new group of workers subject to income requirements for Medicaid and subsidized premiums suppress their earnings to remain eligible, or whether higher thresholds for low-income recipients actually allow them to enter the labor market and work more hours with less fear of losing their insurance. Finally, with retiree health insurance nearly extinct, the extent to which Baby Boomers will take advantage of Medicaid and ACA exchange plans to retire on their own terms will have an important effect on the labor market and the financing of Social Security, so future studies need to watch these trends closely. 


\section{References}

Adams, Scott J. 2004. “Employer-Provided Health Insurance and Job Change.” Contemporary Economic Policy 22(3): 357-369.

Adams, Scott. 2007. "Health Insurance Market Reform and Employee Compensation: The Case of Pure Community Rating in New York.” Journal of Public Economics 91(1): 1119-1133.

Almond, Douglas and Joseph J. Doyle Jr. 2011. "After Midnight: A Regression Discontinuity Design in Length of Postpartum Hospital Stays.” American Economic Journal: Economic Policy 3(3): 1-34.

Anand, Priyanka. 2013. “The Effect of Rising Health Insurance Costs on Compensation and Employment.” Working Paper. New Haven, CT: Yale University.

Andersen, Martin. 2015. "Heterogeneity and the Effect of Mental Health Parity Mandates on the Labor Market.” Journal of Health Economics 43: 74-84.

Autor, David H. and Mark G. Duggan. 2006. "The Growth in the Social Security Disability Rolls: A Fiscal Crisis Unfolding.” Journal of Economic Perspectives 20(3): 71-96.

Ayyagari, Padmaja and Dan M. Shane. 2015. "Does Prescription Drug Coverage Improve Mental Health? Evidence from Medicare Part D.” Journal of Health Economics 41: 46-58.

Baicker, Katherine, Sarah L. Taubman, Heidi L. Allen, Mira Bernstein, Jonathan H. Gruber, Joseph P. Newhouse, Eric C. Schneider, Bill J. Wright, Alan M. Zaslavsky, and Amy N. Finkelstein. 2013. "The Oregon Experiment - Effects of Medicaid on Clinical Outcomes.” New England Journal of Medicine 368(18): 1713-1722.

Baicker, Katherine and Amitabh Chandra. 2006. “The Labor Market Effect of Rising Health Insurance Premiums.” Journal of Labor Economics 24(3): 609-634.

Baicker, Katherine, Amy Finkelstein, Jae Song, and Sarah Taubman. 2014. “The Impact of Medicaid on Labor Market Activity and Program Participation: Evidence from the Oregon Health Insurance Experiment.” American Economic Review 104(5): 322-328.

Bailey, James and Anna Chorniy. 2016. "Employer-Provided Health Insurance and Job Mobility: Did the Affordable Care Act Reduce Job Lock?” Contemporary Economic Policy 34(1): 173-83.

Bartel, Ann, and Paul Taubman. 1979. "Health and Labor Market Success: The Role of Various Diseases.” The Review of Economics and Statistics 61(1): 1-8.

Becker, Gary S. 1964. Human Capital. New York: Columbia University Press. 
Benham, Lee and Alexandra Benham. 1981. "Employment, Earnings and Psychiatric Diagnosis.” In Economic Aspects of Health, Victor Fuchs, ed. Chicago, IL: University of Chicago Press.

Berndt, Ernst R., Stan N. Finkelstein, Paul E. Greenberg, Robert H. Howland, Alison Keith, A. John Rush, James Russell, and Martin B. Keller. 1998. "Workplace Performance Effects from Chronic Depression and its Treatment.” Journal of Health Economics 17: 511-535.

Blank, Rebecca M. 1989. “The Effect of Medical Need and Medicaid on AFDC Participation.” The Journal of Human Resources 24(1): 54-87.

Blau, David M. and Donna Gilleskie. 2001. "The Effect of Health on Employment Transitions of Older Men.” Worker Wellbeing in a Changing Labor Market 5: 35-65.

Blau, David M. and Donna Gilleskie. 2006. "Health Insurance and Retirement of Married Couples.” Journal of Applied Econometrics 21: 935-953.

Blau, David M. and Donna Gilleskie. 2008. "The Role of Retiree Health Insurance in the Employment Behavior of Older Men.” International Economic Review 49(2): 475-514.

Blyler, Crystal, Denise Hoffman, and Gina Livermore. 2013. “Ticket to Work Participants: Then and Now.” Issue Brief 13-01. Washington, DC: Mathematica Policy Research.

Bond, Amelia M. and Chapin White. 2013. "Massachusetts Coverage Expansion Associated with Reduction in Primary Care Utilization among Medicare Beneficiaries.” Health Services Research 48(6 PART1): 1826-1839.

Bound, John. 1989. "The Health and Earnings of Rejected Disability Insurance Applicants.” The American Economic Review 79(3): 482-503.

Bound, John. 1991. "Self-Reported Versus Objective Measures of Health in Retirement Models.” Journal of Human Resources 26: 106-138.

Bound, John, Michael Schoenbaum, and Timothy Waidmann. 1996. "Race Differences in Labor Force Attachment and Disability Status.” The Gerontologist 36: 311-321.

Bound, John, Todd Stinebrickner, and Timothy Waidmann. 2010. "Health, Economic Resources and the Work Decisions of Older Men.” Journal of Econometrics 156(1): 106-129.

Bovjberg, Randall R., Stan Dorn, Juliana Macri, and Jack A. Meyer. 2009. "COBRA Subsidies for Laid-Off Workers: An Initial Report Card.” Working Paper 2009-1. Washington, DC:

The Urban Institute.

Boyle, Melissa A. and Joanna N. Lahey. 2010. "Health Insurance and the Labor Supply Decisions of Older Workers: Evidence from a U.S. Department of Veterans Affairs Expansion.” Journal of Public Economics 94(2010): 467-478. 
Brook, Robert H., John E. Ware Jr., William H. Rogers, Emmett B. Keeler, Allyson R. Davies, Cathy A. Donald, George A. Goldberg, Kathleen N. Lohr, Patricia C. Masthay, and Joseph P. Newhouse. 1983. "Does Free Care Improve Adults' Health? Results from a Randomized Controlled Trial.” New England Journal of Medicine 309(23): 1426-1434.

Brown, Margaret E., Andrew B. Bindman, and Nicole Lurie. 1998. "Monitoring the Consequences of Uninsurance: A Review of Methodologies.” Medical Care Research and Review 55(2): 177-210.

Button, Patrick. 2006. "Expanding Employment Discrimination Protections for Individuals with Disabilities: Evidence from California.” Working Paper No. 1601. New Orleans, LA: Tulane University.

Cai, Lixin. 2010. “The Relationship between Health and Labour Force Participation: Evidence from a Panel Data Simultaneous Equation Model.” Labour Economics 17(1): 77-90.

Card, David, Carlos Dobkin, and Nicole Maestas. 2007. “Does Medicare Save Lives?” Working Paper 13668. Cambridge, MA: National Bureau of Economic Research.

Card, David, Carlos Dobkin, and Nicole Maestas. 2008. “The Impact of Nearly Universal Insurance Coverage on Health Care Utilization and Health: Evidence from Medicare.” American Economic Review 98(5): 2242-2258.

Carroll, Aaron, Austin Frakt, and Samuel Richardson. 2013. "More Medicaid Study Power Calculations (Our Rejected NEJM Letter).” Blog post at The Incidental Economist. Last accessed February 29, 2016. Available at: http://theincidentaleconomist.com/wordpress/more-medicaid-study-power-calculationsour-rejected-nejm-letter/.

Carter, Kristen N., Fiona Imlach Gunasekara, Tony Blakely, and Ken Richardson. 2013. "Health Shocks Adversely Impact Participation in the Labour Force in a Working Age Population: A Longitudinal Analysis.” Australian and New Zealand Journal of Public Health 37(3): 257263.

Case, Anne, Angela Fertig, and Christina Paxson. 2005. "The Lasting Impact of Childhood Health and Circumstance.” Journal of Health Economics 24(2): 365-89.

Chatterji, Pinka, Margarita Alegria, and David Takeuchi. 2011. "Psychiatric Disorders and Labor Market Outcomes: Evidence from the National Comorbidity Survey-Replication.” Journal of Health Economics 30(5): 858-868.

Chirikos, Thomas N. and Gilbert Nestel. 1985. "Further Evidence on the Economic Effects of Poor Health.” Review of Economics and Statistics 67(1): 61-69. 
Coe, Norma B., Wenliang Hou, Alicia H. Munnell, Patrick Purcell, and Matthew S. Rutledge. 2016 (forthcoming). "The Impact of Massachusetts Health Insurance Reform on Labor Mobility and Retirement.” Working Paper. Chestnut Hill, MA: Center for Retirement Research at Boston College.

Coe, Norma B., Mashfiqur R. Khan, and Matthew S. Rutledge. 2013. "Sticky Ages: Why is 65 Still a Retirement Peak?” Working Paper 2013-2. Chestnut Hill, MA: Center for Retirement Research at Boston College.

Coey, Dominic. 2015. “The Effect of Medicaid on Health Care Consumption of Young Adults.” Health Economics 24(5): 558-565.

Coile, Courtney, Kevin S. Milligan, and David A. Wise. 2016. "Health Capacity to Work at Older Ages: Evidence from the U.S.” Working Paper 21940. Cambridge, MA: National Bureau of Economic Research.

Congressional Budget Office. 2014. The Budget and Economic Policy Outlook: 2014-2024. Washington, DC: U.S. Government Printing Office.

Costa, Dora. 1996. “Health and Labor Force Participation of Older Men, 1900-1991.” Journal of Economic History 56: 62-89.

Courtemanche, Charles J. and Daniela Zapata. 2014. "Does Universal Coverage Improve Health? The Massachusetts Experience.” Journal of Policy Analysis and Management 33(1): 36-69.

Currie, Janet and Jonathan Gruber. 1996. "Health Insurance Eligibility, Utilization of Medical Care, and Child Health.” Quarterly Journal of Economics 111(2): 431-466.

Currie, Janet and Jonathan Gruber. 1996. "Saving Babies: The Efficacy and Cost of Recent Changes in the Medicaid Eligibility of Pregnant Women.” Journal of Political Economy 104(6): 1263-1296.

Currie, Janet and Brigitte C. Madrian. 1999. "Health, Health Insurance, and the Labor Market.” Handbook of Labor Economics 3: 3309-3416.

Daneshvary, Nasser and Terrence M. Clauretie. 2007. "Gender Differences in the Valuation of Employer-Provided Health Insurance.” Economic Inquiry 45(4): 800-816.

Dano, Anne Moller. 2005. "Road Injuries and Long-Run Effects on Income and Employment.” Health Economics 14(9): 955-970.

De Boer, Angela G. E. M., Taina Taskila, Anneli Ojajärvi, Frank J. H. Van Dijk, and Jos H. A. M. Verbeek. 2009. "Cancer Survivors and Unemployment: A Meta-Analysis and MetaRegression.” JAMA - Journal of the American Medical Association 301(7): 753-762. 
Decker, Sandra L. 1993. “The Effect of Medicaid on Access to Health Care and Welfare Participation.” Ph.D. Dissertation. Cambridge, MA: Harvard University.

Decker, Sandra L., and Dahlia K. Remler. 2004. "How Much Might Universal Health Insurance Reduce Socioeconomic Disparities in Health? A Comparison of the U.S. and Canada.” Applied Health Economics \& Health Policy 3(4): 205-216.

DeLeire, Thomas and Willard Manning. 2004. "Labor Market Costs of Illness: Prevalence Matters.” Health Economics 13(3): 239-250.

DeLeire, Thomas, Laura Dague, Lindsey Leininger, Kristen Voskuil, and Donna Friedsam. 2013. "Wisconsin Experience Indicates that Expanding Public Insurance to Low-Income Childless Adults Has Health Care Impacts.” Health Affairs 32(6): 1037-1045.

Depew, Briggs. 2015. “The Effect of State Dependent Mandate Laws on the Labor Supply Decisions of Young Adults.” Journal of Health Economics 39: 123-134.

Donohue, Julie M. Yuting Zhang, Aiju Men, Subashan Perera, Judith R. Lave, Joseph T. Hanlon, and Charles F. Reynolds. 2011. "Impact of Medicare Part D on Antidepressant Treatment, Medication Choice, and Adherence among Older Adults with Depression.” The American Journal of Geriatric Psychiatry 19(12): 989-997.

Dor, Avi, Joseph Sudano, and David W. Baker. 2006. "The Effect of Private Insurance on the Health of Older, Working Age Adults: Evidence from the Health and Retirement Study.” Health Services Research 41(3,pt. 1): 759-787.

Douthat, Ross. 2014. "What Health Insurance Might Do.” Blog post at The New York Times. Last accessed February 29, 2016. Available at: http://douthat.blogs.nytimes.com/2014/05/07/what-health-insurance-might-do/.

Dow, Will, Paul Gertler, Robert F. Schoeni, John Strauss, and Duncan Thomas. 1997. "Health Care Prices, Health and Labor Outcomes: Experimental Evidence.” Working Paper Series 97-01. Santa Monica, CA: RAND.

Doyle, Joseph J., Jr. 2005. “Health Insurance, Treatment and Outcomes: Using Auto Accidents as Health Shocks.” Review of Economics and Statistics 87(2): 256-270.

Dubay, Lisa, Sharon K. Long, and Emily Lawton. 2012. "Will Health Reform Lead to Job Loss? Evidence from Massachusetts Says No.” Timely Analysis of Immediate Health Policy Issues Brief. Washington, DC: The Urban Institute.

Elmendorf, Doug. 2014. “Frequently Asked Questions About CBO’s Estimates of the Labor Market Effects of the Affordable Care Act.” Congressional Budget Office blog. Last accessed March 30, 2016. Available at: https://www.cbo.gov/publication/45096. 
Ettner, Susan L. 1997. "Is Working Good for You? Evidence on the Endogneity of Mental and Physical Health to Female Employment.” Working Paper. Cambridge, MA: Harvard School of Public Health.

Fairlie, Robert W., Kanika Kapur, and Susan Gates. 2011. "Is Employer-Based Health Insurance a Barrier to Entrepreneurship?” Journal of Health Economics 30(2011): 146-162.

Farooq, Amaar and Adriana Kugler. 2016. "Beyond Job Lock: Impacts of Public Health Insurance on Occupational and Industrial Mobility.” Working Paper 22118. Cambridge, MA: National Bureau of Economic Research.

Fihn, Stephan D. and John B. Wicher. 1988. "Withdrawing Routine Outpatient Medical Services - Effects on Access and Health.” Journal of General Internal Medicine 3(4): 356-362.

Finkelstein, Amy, et al. 2012. "The Oregon Health Insurance Experiment: Evidence from the First Year.” The Quarterly Journal of Economics 127(3): 1057-1106.

Frakt, Austin. 2014. "Comparing the Massachusetts Mortality Study to the Oregon Medicaid Study.” Blog post at The Incidental Economist. Last accessed February 29, 2016.

Frakt, Austin. 2014. “Improving Health Through Coverage Expansion.” Annals of Internal Medicine 160(9): 649-650.

French, Eric. 2005. “The Effects of Health, Wealth, and Wages on Labour Supply and Retirement Behaviour.” Review of Economic Studies 72(2): 395-427.

French, Eric and John Bailey Jones. 2011. “The Effects of Health Insurance and Self-Insurance on Retirement Behavior.” Econometrica 79(3): 693-732.

French, Eric and Jae Song. 2014. "The Effect of Disability Insurance Receipt on Labor Supply.” American Economic Journal - Economic Policy 6(2): 291-337.

García-Gómez, Pilar, Hans van Kippersluis, Owen O'Donnell, and Eddy van Doorslaer. 2013. “Long- Term and Spillover Effects of Health Shocks on Employment and Income.” Journal of Human Resources 48(4): 873-909.

Garthwaite, Craig, Tal Gross, and Matthew J. Notowidigdo. 2014. "Public Health Insurance, Labor Supply, and Employment Lock.” The Quarterly Journal of Economics 2014: 653696.

Goetzel, Ron Z. et al. 2004. "Health, Absence, Disability, and Presenteeism Cost Estimates of Certain Physical and Mental Health Conditions Affecting U.S. Employers.” Journal of Occupational and Environmental Medicine 46(4): 398-412. 
Goldman, Dana P., Jayanta Bhattacharya, Daniel F. McCaffrey, Naihua Duan, Arleen A. Leibowitz, Geoffrey F. Joyce, and Sally C. Morton. 2001. "Effect of Insurance on Mortality in an HIV-Positive Population in Care.” Journal of the American Statistical Association 96(455): 883-94.

Grossman, Michael. 1972. "On the Concept of Health Capital and the Demand for Health.” The Journal of Political Economy 80(2): 223-255.

Gruber, Jonathan. 2000. "Health Insurance and the Labor Market." Handbook of Health Economics 1: 646-706.

Gruber, Jonathan and Brigitte C. Madrian. 1994. "Health Insurance and Job Mobility: The Effects of Public Policy on Job-Lock.” Industrial and Labor Relations Review 48(1): 86102.

Gruber, Jonathan and Brigitte C. Madrian. 1997. "Employment Separation and Health Insurance Coverage.” Journal of Public Economics 66(3): 349-382.

Gruber, Jonathan and Brigitte C. Madrian. 2004. "Health Insurance, Labor Supply, and Job Mobility: A Critical Review of the Literature.” Working Paper 8817. Cambridge, MA: National Bureau of Economic Research.

Haas, Jennifer S., I. Steven Udvarhelyi, Carl N. Morris, and Arnold M. Epstein. 1993a. "The Effect of Providing Health Coverage to Poor Uninsured Pregnant Women in Massachusetts.” JAMA: The Journal of the American Medical Association 269(1): 87-91.

Haas, Jennifer S., Steven Udvarhelyi, and Arnold M. Epstein. 1993b. “The Effect of Health Coverage for Uninsured Pregnant Women on Maternal Health and the Use of Cesarean Section.” JAMA: The Journal of the American Medical Association 270(1): 61-64.

Hadley, Jack. 2003. "Sicker and Poorer - The Consequences of Being Uninsured: A Review of the Research on the Relationship Between Health Insurance, Medical Care Use, Health, Work, and Income.” Medical Care Research and Review 60(2 SUPPL.): 3S-75S.

Hadley, Jack and Timothy Waidmann. 2006. "Health Insurance and Health at Age 65: Implications for Medical Care Spending on New Medicare Beneficiaries.” Health Services Research 41(2): 429-451.

Hamersma, Sarah and Matthew Kim. 2009. "The Effect of Parental Medicaid Expansions on Job Mobility.” Journal of Health Economics 28(2009): 761-770.

Hanratty, Maria J. 1996. “Canadian National Health Insurance and Infant Health.” American Economic Review 86(1): 276-84. 
Heim, Bradley and LeeKai Lin. 2014. "Does Health Reform Lead to an Increase in Early Retirement? Evidence from Massachusetts.” Working Paper 2014-1. Bloomington, IN: Indiana University.

Heim, Bradley and Ithai Lurie. 2010. "The Effect of Self-Employed Health Insurance Subsidies on Self-Employment.” Journal of Public Economics 94(2010): 995-1007.

Heim, Bradley, Ithai Lurie, and Kosali Simon. 2015. "The Impact of the Affordable Care Act Young Adult Provision on Labor Market Outcomes: Evidence from Tax Data.” In Tax Policy and the Economy Volume 29, Jeffrey R. Brown, ed. Chicago, IL: University of Chicago Press.

Holahan, John and Linda Blumberg. 2006. "Massachusetts Health Care Reform: A Look at the Issues." Health Affairs 25(6): w432-w443.

Holtz-Eakin, Douglas, John R. Penrod, and Harvey S. Rosen. 1996 "Health Insurance and the Supply of Entrepreneurs.” Journal of Public Economics 62(1-2): 209-235.

Institute of Medicine (IOM). 2002. Care without Coverage: Too Little, Too Late. Washington, DC: National Academy Press.

Joffe-Walt, Chana. 2013. "Unfit for Work: The Starting Rise of Disability in America.” National Public Radio blog post, April 1, 2013. Last accessed March 30, 2016. Available at: http://apps.npr.org/unfit-for-work/.

Jolls, Christine and J.J. Prescott. 2004. "Disaggregating Employment Protection: The Case of Disability Discrimination.” Working Paper 10740. Cambridge, MA: National Bureau of Economic Research.

Kapur, Kanika 2004. “The Impact of the Health Insurance Market on Small Firm Employment.” Journal of Risk and Insurance 71(1): 63-90.

Keeler, Emmett B., Robert H. Brook, George A. Goldberg, Caren J. Kamberg, and Joseph P. Newhouse. 1985. "How Free Care Reduced Hypertension in the Health Insurance Experiment.” Journal of the American Medical Association 254(14): 1926-1931.

Kolstad, Jonathan T. and Amanda E. Kowalski. 2012. "Mandate-Based Health Reform and the Labor Market: Evidence from the Massachusetts Reform.” Working Paper 17933. Cambridge, MA: National Bureau of Economic Research.

Kreider, Brent. 1996. “Latent Work Disability and Reporting Bias.” Working Paper. Charlottesville, VA: University of Virginia.

Kruse, Douglas and Lisa Schur. 2003. "Employment of People with Disabilities Following the ADA.” Industrial Relations 42(1): 31-64. 
Lehrer, Steven F. and Nuno Sousa Pereira. 2007. "Worker Sorting, Compensating Differentials and Health Insurance: Evidence from Displaced Workers.” Journal of Health Economics 26(5): 1034-1056.

Levy, Helen and David Meltzer. 2008. “The Impact of Health Insurance on Health.” American Review of Public Health 29: 399-409.

Levy, Helen, Thomas Buchmueller, and Sayeh Nikpay. 2015. "The Effect of Health Reform and Retirement.” Working Paper 2015-329. Ann Arbor, MI: Michigan Retirement Research Center.

Lluis, Stephanie and Jean Abraham. 2013. "The Wage-Health Insurance Trade-Off and Worker Selection: Evidence from the Medical Expenditure Panel Survey 1997 to 2006.” Industrial Relations 52(2): 541-581.

Long, Sharen K. and Karen Stockley. 2011. "The Impacts of State Health Reform Initiatives on Adults in New York and Massachusetts.” Health Services Research 46(1 PART 2): 365387.

Long, Sharon K., Karen Stockley, and Heather Dahlen. 2012. "Massachusetts Health Reforms: Uninsurance Remains Low, Self-Reported Health Status Improves as State Prepares to Tackle Costs." Health Affairs 31(2): 444-451.

Lubotsky, Darren and Craig A. Olson. 2015. "Premium Copayments and the Trade-Off between Wages and Employer-Provided Health Insurance.” Journal of Health Economics 44: 63-79.

Lurie, Nicole, N. B. Ward, Martin F. Shapiro, C. Gallego, R. Vaghaiwalla, and Robert H. Brook. 1986. “Termination of Medi-Cal Benefits. A Follow-Up Study One Year Later.” New England Journal of Medicine 314(19): 1266-1268.

Madrian, Brigitte C. and Lars John Lefgren. 1998. "The Effect of Health Insurance on Transitions to Self Employment.” Working Paper. Chicago, IL: University of Chicago.

Maestas, Nicole, Kathleen J. Mullen, and Alexander Strand. 2013. "Does Disability Insurance Receipt Discourage Work? Using Examiner Assignment to Estimate Causal Effects of SSDI Receipt.” American Economic Review 103(5): 1797-1829.

Maurer, Jurgen, Roger Klein, and Francis Vella. 2011. "Subjective Health Assessments and Active Labor Market Participation of Older Men: Evidence from a Semiparametric Binary Choice Model with Nonadditive Correlated Individual-Specific Effects.” Review of Economics and Statistics 93(3): 764-774.

McArdle, Megan. 2014. “Obamacare Might Help You Live Longer.” Blog post at Bloomberg View. Last accessed February 29, 2016. 
McWilliams, J. Michael 2009. "Health Consequences of Uninsurance Among Adults in the United States: Recent Evidence and Implications.” Milbank Quarterly 87(2): 443-494.

McWilliams, J. Michael, Ellen Meara, Alan M. Zaslavsky, and John Z. Ayanian. 2007. "Health of Previously Uninsured Adults after Acquiring Medicare Coverage.” Journal of the American Medical Association 298(24): 2886-94.

McWilliams, J. Michael, Alan M. Zaslavsky, and Haiden A. Huskamp. 2011. "Implementation of Medicare Part D and Nondrug Medical Spending for Elderly Adults with Limited Prior Drug Coverage.” Journal of the American Medical Association 306(4): 402-409.

Mehnert, Anja. 2011, "Employment and Work-Related Issues in Cancer Survivors." Critical Reviews in Oncology/Hematology 77(2): 109-130.

Meyer, Bruce D. and Dan T. Rosenbaum. 2000. "Making Single Mothers Work: Recent Tax and Welfare Policy and Its Effects.” Working Paper No. 7491. Cambridge, MA: National Bureau of Economic Research.

Miller, Sarah. 2012. "The Effect of the Massachusetts Reform on Health Care Utilization.” Inquiry 49(4): 317-326.

Miller, Sarah. 2012. "The Impact of the Massachusetts Health Care Reform on Health Care Use Among Children.” American Economic Review: Papers \& Proceedings 102(3): 502-507.

Montgomery, E. and J.C. Navin. 2000. "Cross-State Variation in Medicaid Programs and Female Labor Supply.” Economic Inquiry 38(3): 402-418.

Moran, John R., Pamela Farley Short, and Christopher S. Hollenbeak. 2011. "Long-Term Employment Effects of Surviving Cancer.” Journal of Health Economics 30(3): 505-514.

Munnell, Alicia, Geoffrey T. Sanzenbacher, and Matthew S. Rutledge. 2015. "What Causes Workers to Retire Before They Plan?” Working Paper 2015-22. Chestnut Hill, MA: Center for Retirement Research at Boston College.

Newhouse, Joseph P. and the Insurance Experiment Group. 1993. Free for All? Lessons from the RAND Health Insurance Experiment. Cambridge, MA: Harvard University Press.

Niu, Xiaotong. 2014. "Health Insurance and Self-Employment: Evidence from Massachusetts." Industrial and Labor Relations Review 67(4): 1235-1273.

O'Brien, Ellen. 2003. “Employers’ Benefits from Workers' Health Insurance.” Milbank Quarterly 81(1): 5-43.

Olson, Craig A. 2002. "Do Workers Accept Lower Wages in Exchange for Health Benefits?" Journal of Labor Economics 20(2): S91-S114. 
Oyer, Paul. 2008. “Salary or Benefits?” Research in Labor Economics 28: 429-467.

Pauly, Mark V. 2005. "Effects of Insurance Coverage on Use of Care and Health Outcomes for Nonpoor Young Women.” American Economic Review 95(2): 219-223.

Pelkowski, Jodi Messer and Mark C. Berger. 2004. "The Impact of Health on Employment, Wages, and Hours Worked over the Life Cycle.” Quarterly Review of Economics and Finance 44(1): 102-21.

Polsky, Daniel, Jalpa A. Doshi, José Escarce, Willard Manning, Susan M. Paddock, Liyi Cen, and Jeannette Rogowski. 2006. "The Health Effects of Medicare for the New-Elderly Uninsured.” Working Paper 12511. Cambridge, MA: National Bureau of Economic Research.

Ruhm, Christopher J. 1992. "The Effects of Physical and Mental Health on Female Labor Supply.” In Economics and Mental Health, Richard G. Frank and Willard G. Manning, eds. Baltimore, MD: Johns Hopkins Press.

Rust, John and Christopher Phelan. 1997. "How Social Security and Medicare Affect Retirement Behavior in a World of Incomplete Markets.” Econometrica 65: 781-831.

Sachs, Rebecca Marqusee. 2013. "Job-Lock and Health Insurance Premiums: Evidence from the Massachusetts Health Care Reform.” Working Paper. Stanford, CA: Stanford University Department of Economics.

Sanz-de-Galdeano, Anna. 2006. "Job-Lock and Public Policy: Clinton’s Second Mandate.” Industrial and Labor Relations Review 59(3): 430-437.

Sanzenbacher, Geoffrey T. 2014. "What We Know About Health Reform in Massachusetts." Issue in Brief 14-9. Chestnut Hill, MA: Center for Retirement Research at Boston College.

Short, Pamela Farley, Joseph J. Vasey, and John R. Moran. 2008. "Long-Term Effects of Cancer Survivorship on the Employment of Older Workers." HSR: Health Services Research 43(1 Part I): 193-210.

Smith, Jessica C. and Carla Medalia. 2015. "Health Insurance Coverage in the United States: 2014.” Report No. P60-253. Washington, DC: U.S. Department of Commerce.

Sommers, Benjamin D., Sharon K. Long, and Katherine Baicker. 2014. "Changes in Mortality after Massachusetts Health Care Reform : A Quasi-Experimental Study.” Annals of Internal Medicine 160(9): 585-593.

Stapleton, David, Gina Livermore, Craig Thornton, Bonnie O’Day, Robert Weathers, Krista Harrison, So O’Neil, Emily Sama Martin, David Wittenburg, and Debra Wright. 2008. "Ticket to Work at the Crossroads: A Solid Foundation with an Uncertain Future.” Working Paper. Washington, DC: Mathematica Policy Research. 
Stapleton, David, Su Liu, Dawn Phelps, and Sarah Prenovitz. 2010. "Work Activity and Use of Employment Supports Under the Original Ticket to Work Regulations: Longitudinal Statistics for New Social Security Disability Insurance Beneficiaries.” Working Paper. Washington, DC: Mathematica Policy Research.

Strumpf, Erin. 2011. "Medicaid's Effect on Single Women's Labor Supply: Evidence from the Introduction of Medicaid.” Journal of Health Economics 30(2011): 531-548.

Taubman, Sarah L., Heidi L. Allen, Bill J. Wright, Katherine Baicker, and Amy N. Finkelstein. 2014. "Medicaid Increases Emergency-Department Use: Evidence from Oregon's Health Insurance Experiment.” Science 343(6168): 263-268.

Van der Wees, Philip J., Alan M. Zaslavsky, and John Z. Ayanian. 2013. "Improvements in Health Status after Massachusetts Health Care Reform.” Milbank Quarterly 91(4): 663-689.

Velamuri, Melathia. 2012. "Taxes, Health Insurance, and Women’s Self-Employment.” Contemporary Economic Policy 30(2): 162-177.

Volpp, Kevin G.M., Sankey V. Williams, Joel Waldfogel, Jeffrey H. Silber, J. Sanford Schwartz, and Mark V. Pauly. 2003. "Market Reform in New Jersey and the Effect on Mortality from Acute Myocardial Infarction.” Health Services Research 38(2): 515-533.

Wang, Chao, Qing Li, Arthur Sweetman, and Jermiah Hurley. 2015. "Mandatory Universal Drug Plan, Access to Health Care and Health: Evidence from Canada." Journal of Health Economics 44: 80-96.

Weathers, Robert R. II, Chris Silanskis, Michelle Stegman, John Jones, and Susan Kalasunas. 2010. "Expanding Access to Health Care for Social Security Disability Insurance Beneficiaries: Early Findings from the Accelerated Benefits Demonstration.” Social Security Bulletin 70(4): 25-47.

Xu, Xiao and Gail A. Jensen. 2012. "Does Health Insurance Reduce Illness-Related Worker Absenteeism?” Applied Economics 44(35): 4591-4603.

Yelowitz, Aaron S. 1995. "The Medicaid Notch, Labor Supply, and Welfare Participation: Evidence from Eligibility Expansions.” The Quarterly Journal of Economics 110(4): 909939.

Zimmer, David M. 2015. "Does COBRA Reduce the Probability that Job Separators Return to Work?” Journal of Economic Policy Reform 18(4): 326-340.

Zimmer, David M. 2015. "Employment Effects of Health Shocks: The Role of Fringe Benefits.” Bulletin of Economic Research 67(4): 346-358. 
Zissimopolous, Julie M. and Lynn A. Karoly. 2007. "Transitions to Self-Employment at Older Ages: The Role of Wealth, Health, Health Insurance, and Other Factors.” Labour Economics 14(2007): 269-295. 


\section{RECENT WORKING PAPERS FROM THE CENTER FOR RETIREMENT RESEARCH AT BOSTON COLLEGE}

Labor Force Dynamics in the Great Recession and Its Aftermath: Implications for Older Workers

Gary Burtless, July 2016

Elderly Poverty in the United States in the 21st Century: Exploring the Role of Assets in the Supplemental Poverty Measure

Christopher Wimer and Lucas Manfield, November 2015

The Economic Burden of Out-of-Pocket Medical Expenditures Before and After Implementation of the Medicare Prescription Drug Program

Ayse Akincigil and Karen Zurlo, November 2015

The Impact of Temporary Assistance Programs on the Social Security Claiming Age

Geoffrey T. Sanzenbacher, April Yanyuan Wu, and Matthew S. Rutledge, October 2015

Do Households Increase Their Savings When the Kids Leave Home?

Irena Dushi, Alicia H. Munnell, Geoffrey T. Sanzenbacher, and Anthony Webb, September 2015

Evaluating the Impact of Social Security Benefits on Health Outcomes Among the Elderly Padmaja Ayyagari, September 2015

Does Age-Related Decline in Ability Correspond with Retirement Age?

Anek Belbase, Geoffrey T. Sanzenbacher, and Christopher M. Gillis, September 2015

Job Polarization and Labor Market Outcomes for Older, Middle-Skilled Workers Matthew S. Rutledge and Qi Guan, September 2015

What Causes Workers to Retire Before They Plan?

Alicia H. Munnell, Geoffrey T. Sanzenbacher, and Matthew S. Rutledge, September 2015

Calculating Neutral Increases in Retirement Age by Socioeconomic Status

Geoffrey T. Sanzenbacher, Anthony Webb, Candace M. Cosgrove, and Natalia S. Orlova, August 2015

How Does Occupational Access for Older Workers Differ by Education?

Matthew S. Rutledge, Steven A. Sass, and Jorge D. Ramos-Mercado, August 2015

How Much Longer Do People Need to Work?

Alicia H. Munnell, Anthony Webb, and Anqi Chen, August 2015

All working papers are available on the Center for Retirement Research website (http://crr.bc.edu) and can be requested by e-mail (crr@bc.edu) or phone (617-552-1762). 